\title{
Influence of school backpacks on spinal column load in primary school students
}

\author{
Fikret Veljovic $^{1}$, Senad Burak ${ }^{1}$, Avdo Voloder ${ }^{1}$, Benjamin Kulovac ${ }^{3}$, Dzenan Jahic ${ }^{4}$, Faris Kadic ${ }^{5}$ \\ ${ }^{1}$ Faculty of Mechanical Engineering, University of Sarajevo, Sarajevo, Bosnia and Herzegovina \\ ${ }^{2}$ Faculty of Sport and Physical Education, University of Sarajevo, Sarajevo, Bosnia and Herzegovina \\ ${ }^{3}$ Faculty of Medical Studies, University of Sarajevo, Sarajevo, Bosnia and Herzegovina \\ ${ }^{4}$ Faculty of Sport and Physical Education, University of Sarajevo, Bosnia and Herzegovina \\ ${ }^{5}$ Health Care Centre, Sarajevo, Bosnia and Herzegovina
}

\begin{abstract}
Background: The problem of heavy school bags is a global problem recognized in many countries in Europe and the world, including in Bosnia and Herzegovina. In addition to poor posture habits, "sedentary lifestyles" and insufficient physical activity, school bags is one of the main causes of low back pain and deformity in pupils. The recommendation of the World Health Organization (WHO) is that the weight of the school bag should not exceed $10 \%$ of the student's weight. However, in practice these limitations are far from reality with the obvious problems caused by too heavy bags. The aim of the paper is to identify and analyze the backbone load caused by the overweight school backpacks in real school work conditions and eliminate them by creating new solutions that are in line with ergonomic and biomechanical principles, as well as the recommendation given by WHO.
\end{abstract}

Methods: The research included first grade primary school students at the age of seven, including their parents. The research began by interviewing parents with relevant questions, as well as measuring the students' height and weight and the weight of their school backpacks. The analysis was performed in CATIA v5 software package (Dassault Systèmes, Vélizy-Villacoublay, France) using its advanced biomechanical modules. By knowing the anthropometric and work environment data with ergonomic design and analysis, the biomechanical analysis, rapid upper limb assessment (RULA) and carry analysis were performed.

Results: The conducted survey showed that $84 \%$ of students walk from home to school nineteen minutes on average and that $77 \%$ of them carry their school backpacks independently. Based on the measurements, it has been shown that, on average, the weight of the school backpacks is well above the WHO recommendation. A study conducted on a representative sample of students confirmed the relation between fatigue and spinal pain caused by carrying a heavy school bag. Computer analysis showed excessive loads on the spinal segment of L4/L5 that were outside the normal range of $3,400 \mathrm{~N}$.

Conclusions: A simulated computer analysis using RULA and biomechanical analysis with calculations of maximum loads in the lumbar segment of students found that school backpacks carried by students were too heavy for their age and well beyond the normal limits and WHO recommendations. The analysis showed that it is necessary to reduce the weight of the bag by about $30 \%$.

\section{Corresponding Author:} \\ Fikret Veljović, \\ Faculty of Mechanical Engineering, \\ University of Sarajevo, \\ Vilsonovo šetalište 9, 71000 Sarajevo, Bosnia \\ E-mail: veljovic@mef.unsa.ba
}

Keywords: $\quad$ Musculoskeletal system, Lumbar-load analysis, Ergonometric

\section{Introduction}

The weight of the school backpacks is a problem that has been recognized in many countries which have proposed preventive measures and appropriate actions to ensure the normal development and health of the students. However, it has been noticed that in Bosnia and Herzegovina, from year to year the amount of not only compulsory but also additional school material that students carry in their backpacks is significantly increasing. The World Health Organization recommends that this weight should not exceed 10\% of the child's 
weight, which is also demonstrated in academic research $(1,2)$. The actual weight of backpacks carried by students has been shown to be in the range of $30 \%$ to $40 \%$ of their body weight (3), which creates excessive load on the spine (4). Exercises adversely affect children's bodies, cause fatigue, exhaustion, low back pain and create difficulties in walking and maintaining balance $(1,2,5,6)$.

Today's students' lifestyles are characterized by reduced physical activity where they spend a lot of time sitting (working at a computer, cellphone, watching television, etc.), which, given irregular and unbalanced diet, causes many developmental problems and spinal pain. It should be emphasized that the organism of children develops intensively at this age, and this type of loading further affects disorders of the musculoskeletal system (7). A school backpack that is too heavy and unsuitable for schoolchildren can lead to spinal stress, lumbar spine, shoulder pain and create all kind of health problems that will affect the quality of life of today's schoolchildren in the future. The method of carrying a school backpack is also very important, as students can carry their backpack on both shoulders, on one shoulder, over their shoulders or in one hand only (7).

All of these ways of carrying a school backpack create different loads that lead to improper posture, that is, deformity. Most often, children carry backpacks from home to school and vice versa, so the backpack should meet their needs without interfering with walking, muscle tension, poor circulation or difficulty breathing (8). In addition, it should be emphasized that kyphotic and balanced posture dominates at seven to eight years of age, and in the case of overload, early disorders of musculoskeletal system development may already occur (9). It is necessary to prevent disorders in the growth and development of the child $(1,3,5,9)$.

\section{Aim}

The aim of the paper is to identify and analyze the backpack load caused by the backpack in actual school work conditions and eliminate them by creating new solutions that are in line with ergonomic and biomechanical principles.

\section{Methods}

The research in this paper is based on the data collected by first grade students at Sarajevo's First Elementary School and on the simulated analysis with load results in the lumbar segment L4 / L5 caused by carrying a school backpack.

The analysis was performed in the CATIA v5 software solution (Dassault Systèmes, Vélizy-Villacoublay, France) using the RULA assessment tool biomechanical analysis. For the purposes of this paper, data collection was performed in two parts. The students were not interviewed, the survey was conducted with their parents, primarily because the children were not adults enough to obtain reliable and relevant data based on their answers. The first grade students were interviewed to discuss the weight of the backpack, whether they were tired when carrying the bag, and whether they were experiencing certain muscle and spine pain.

\section{Results}

First grade elementary school student, average age 7 years, average body weight $32(\mathrm{~kg})$ and average height $134(\mathrm{~cm})$, five days a week during the school year walking from home to school and vice versa for an average of 20 minutes, carrying a school bag on his/jer shoulders with an average weight of $3.8(\mathrm{~kg})$. The load factor is 1.3. The specific positions that are relevant are lifting the school bag on the shoulders, carrying the school bag on both shoulders, and putting down the bag on arrival at school and at home. For these characteristics, an appropriate computer model was designed and RULA and biomechanical analysis were performed. The analysis showed that it is necessary to reduce the weight of the bag by about $30 \%$.

\subsection{Analysis of first body position}

In this position, the student lifts the backpack with both hands and places it on his shoulders, as shown on the Figure 1.b. Several risk factors are examined during the RULA analysis, including the number of repetitions, static muscle load, force, working position, and no-break time. All these factors are combine to produce a final result, ranging from 1 to 7 (Figure 1.a). These values are assigned to the appropriate colors of green, yellow, orange and red. Green indicates that the student's position is acceptable, yellow indicates that he or she needs to continue the analysis, orange indicates that a change of position will be probably necessary, while red indicates that a change of position is required. 

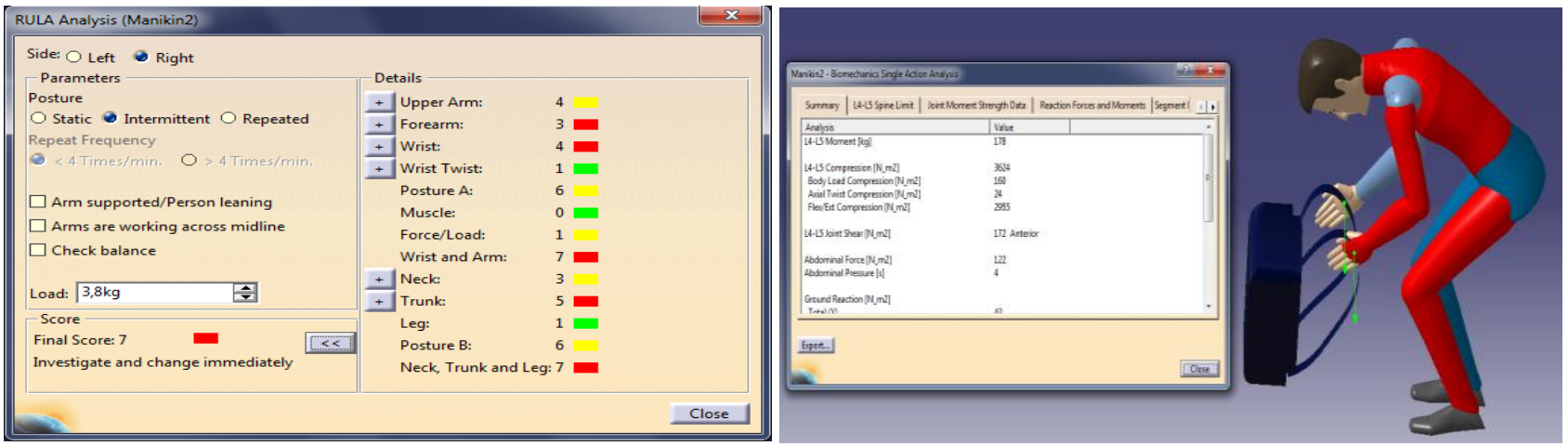

Figure 1. First body position - results of RULA (a) and biomechanical (b) analysis of loaded student body parts when lifting a school backpack

As it can be seen, the final result of the RULA analysis for a given position is indicated by size 7 (red), which means that a new analysis is desirable after changing the input parameters or position.

\subsection{Analysis of second body position}

In this position, the student carries a school backpack on his back on the way from home to school and vice versa (Figure 2).

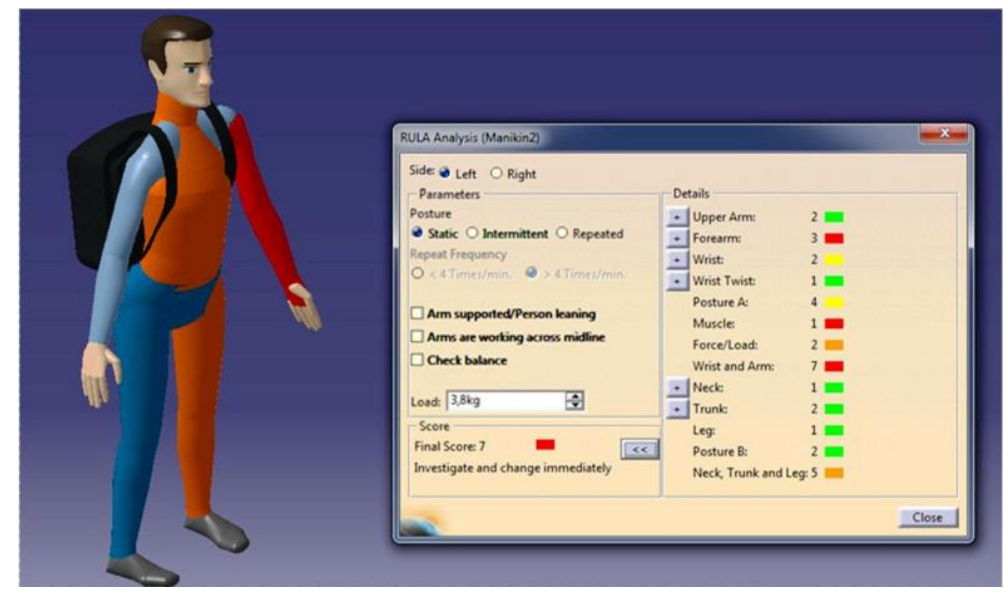

Figure 2. Second body position - results of RULA analysis and loaded student body parts when carrying a bag on both shoulders

The RULA analysis indicates this placement as an excessive student workload. In order to establish the values of the load on the lumbar part of the spinal column (segment L4/L5), as well as the calculation of intraabdominal pressure (IAP), biomechanical Single Action Analysis is performed. In doing so, intra-abdominal pressure is calculated using the formula IAP $=0.079 * \mathrm{Ml}-1.127[\mathrm{kPa}]$.

Table 1. L4 / L5 lumbar torque and intra-abdominal pressure (IAP) values of first-grade students before improvement / after improvement

\begin{tabular}{l|ccc}
\hline \multirow{2}{*}{ Position } & Time $[\mathrm{min}]$ & $\begin{array}{c}\text { Lumbar torque } \\
\text { L4/L5 }[\mathrm{Nm}]\end{array}$ & IAP[kPa] \\
\hline \multirow{3}{*}{ Lifting the bag } & 0.00 & $178 / 150$ & $12.94 / 10.72$ \\
\cline { 2 - 4 } & 0.03 & $166 / 141$ & $11.99 / 10.01$ \\
\cline { 2 - 4 } & 0.04 & $142 / 125$ & $1.09 / 8.75$ \\
\cline { 2 - 4 } Carrying the bag & 0.05 & $110 / 90$ & $7.56 / 5.98$ \\
\cline { 2 - 4 } & 1.00 & $103 / 88$ & $7.01 / 5.83$ \\
\cline { 2 - 4 } & 5.00 & $95 / 79$ & $6.38 / 5.11$ \\
\hline
\end{tabular}




\begin{tabular}{c|ccc}
\hline \multirow{4}{*}{ Lowering the bag } & 15.00 & $89 / 73$ & $5.90 / 4.64$ \\
\cline { 2 - 4 } & 20.00 & $85 / 71$ & $5.59 / 4.48$ \\
\cline { 2 - 4 } & 20.05 & $95 / 84$ & $6.38 / 5.51$ \\
\cline { 2 - 4 } & 20.04 & $104 / 90$ & $7.09 / 5.98$ \\
\hline
\end{tabular}
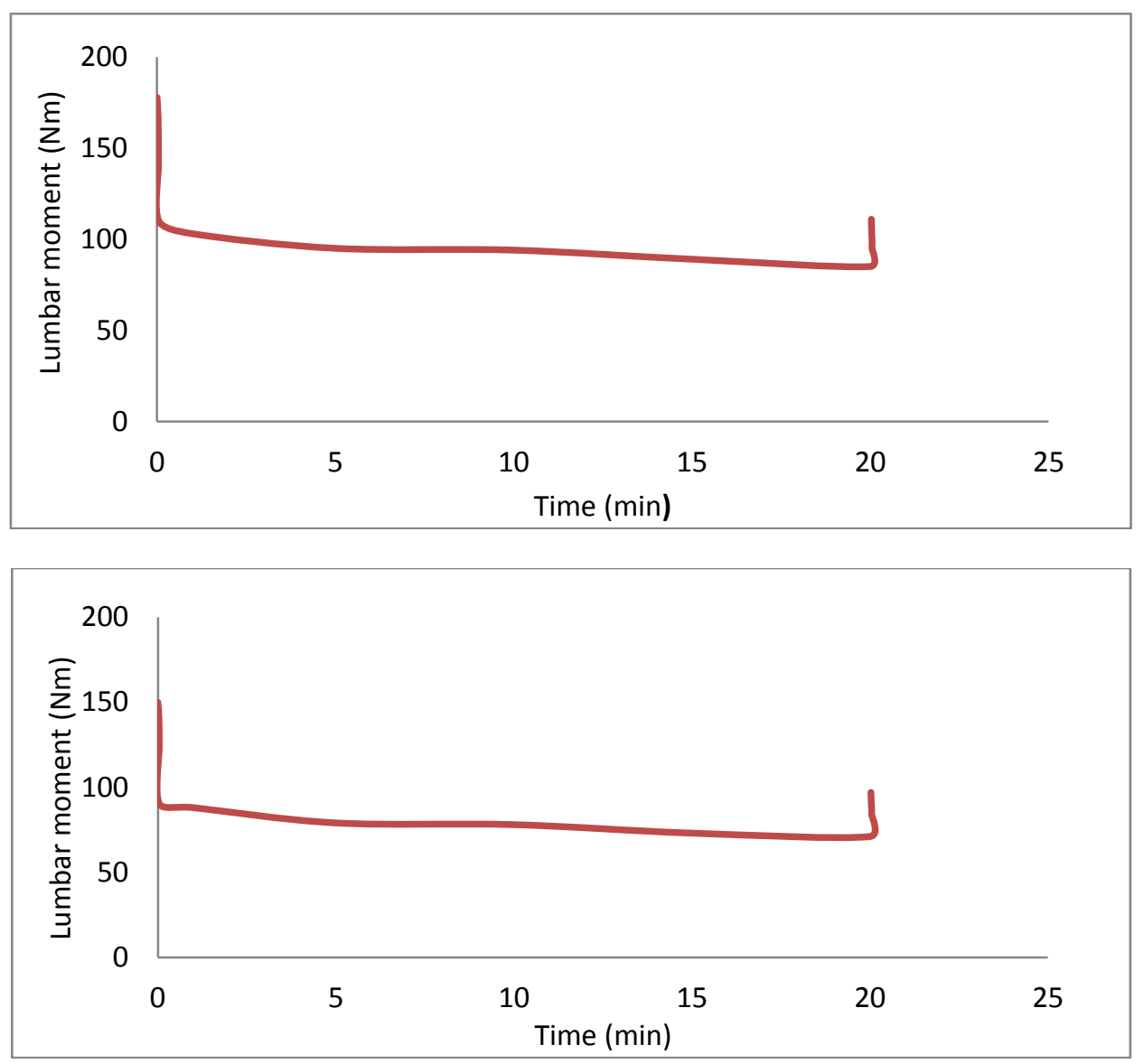

Figure 3. Graphical representation of L4/L5 torque values for first grade students before (a) and after (b) improvement

Table 2. Maximum load expressed in compression force at site L4 / L5 before (a) and after (b) improvement

\begin{tabular}{lr|lr}
\hline \multicolumn{2}{c|}{ Before improvement (a) } & \multicolumn{2}{c}{ After improvement (b) } \\
\hline L4-L5 Moment [Nm] & 178 & L4-L5 Moment [Nm] & 150 \\
\hline L4-L5 Compression [N] & 3,624 & L4-L5 Compression [N] & 3,101 \\
\hline Body Load Compression [N] & 160 & Body Load Compression [N] & 139 \\
\hline Axial Twist Compression [N] & 24 & Axial Twist Compression [N] & 19 \\
\hline Flex/Ext Compression [N] & 2,955 & Flex/Ext Compression [N] & 2,107 \\
\hline
\end{tabular}

Table 2 shows that the maximum lumbar torque of $178[\mathrm{Nm}]$ when lifting the school backpack and the compression of L4/L5 is 3,624 [N]. This value is inappropriate because the maximum allowable compression force is $3,400[\mathrm{~N}]$ and therefore the student load must be reduced.

After improvement, it can be seen from Table 2 that the maximum lumbar torque is reduced to $150[\mathrm{Nm}]$ and that the compression in the L4/L5 area is reduced to 3,101 [N]. This value is satisfactory since the maximum allowable compression force is up to 3,400 [N].

Hand load moments and lumbar torque values in the L4/L5 segment, i.e. critical locations that suffer the highest load and where the most energy is consumed in lifting and lowering activities, are given in Table 3. 
Table 3. Hand load and lumbar torque L4/L5 due to the lifting, carrying and lowering of the school backpack before / after improvement

\begin{tabular}{|c|c|c|c|c|c|}
\hline \multicolumn{3}{|c|}{ Loads on the arms } & $\begin{array}{l}\text { Lifting the bag } \\
\text { [Nm] }\end{array}$ & $\begin{array}{c}\text { Carrying the } \\
\text { bag }[\mathrm{Nm}]\end{array}$ & $\begin{array}{l}\text { Lowering the } \\
\text { bag }[\mathrm{Nm}]\end{array}$ \\
\hline \multirow[b]{2}{*}{ Joint } & \multirow{2}{*}{ Right } & flexion - extension & $12 / 9$ & $5 / 4$ & $11 / 10$ \\
\hline & & radial movement & $11 / 11$ & $5 / 3$ & $13 / 12$ \\
\hline \multirow{2}{*}{ hands } & \multirow{2}{*}{ Left } & flexion - extension & $12 / 11$ & $3 / 3$ & $11 / 10$ \\
\hline & & radial movement & $11 / 9$ & $6 / 4$ & $13 / 13$ \\
\hline \multirow{4}{*}{ Elbow } & \multirow{2}{*}{ Right } & flexion - extension & $48 / 45$ & $23 / 23$ & $40 / 37$ \\
\hline & & twist & $3 / 2$ & $3 / 0$ & $3 / 2$ \\
\hline & \multirow{2}{*}{ Left } & flexion - extension & $52 / 48$ & $20 / 19$ & $46 / 46$ \\
\hline & & twist & $2 / 2$ & $2 / 0$ & $2 / 2$ \\
\hline \multirow{6}{*}{ Shoulder } & \multirow{3}{*}{ Right } & flexion - extension & $55 / 48$ & $31 / 33$ & $51 / 51$ \\
\hline & & right-left twist & $30 / 31$ & $2 / 2$ & $28 / 28$ \\
\hline & & internal-external rotation & $3 / 3$ & $0 / 0$ & $3 / 3$ \\
\hline & \multirow{3}{*}{ Left } & flexion - extension & $56 / 56$ & $30 / 28$ & $49 / 45$ \\
\hline & & right-left twist & $32 / 29$ & $1 / 1$ & $30 / 31$ \\
\hline & & internal-external rotation & $1 / 0$ & $0 / 0$ & $1 / 1$ \\
\hline & \multicolumn{2}{|c|}{ Lumbar moment on L4/L5 [Nm] } & $178 / 150$ & $103 / 88$ & $111 / 97$ \\
\hline \multirow{2}{*}{\multicolumn{3}{|c|}{ Sum of internal work of the arms $[\mathrm{Nm}]$}} & $328 / 304$ & $131 / 120$ & $301 / 291$ \\
\hline & & & & $1,152 / 1,050$ & \\
\hline
\end{tabular}

The total work to be done on the joints of the hands and the load in the spine on the L4/L5 segments before improving / after improving the posture is 1,152.00/1,050.00 [Nm]. The force in the hands when lifting, rotating, carrying, and lowering the school bag is:

$$
F_{\text {hands }}=m \cdot g=3.8 \cdot 9.81=37 / 26[\mathrm{~N}] \text {. }
$$

The distance that the arms cross carrying the load represents the lengths the student crosses from the moment of lifting, carrying and lowering the load. Work performed during those operations is a product of the force of hand $\left(F_{\text {hands }}\right)$ and of the distance $(s)$, namely:

$$
A=F_{\text {hands }} \cdot s
$$

The results of the calculation are given in Table 4 .

Table 4. Work spent on hands when going to school and carrying a school bag before / after improvement

\begin{tabular}{lccc}
\hline & Lifting the bag & Carrying the bag & Lowering the bag \\
\hline Force in hands $[\mathrm{N}]$ & $37 / 26$ & $37 / 26$ & $37 / 26$ \\
\hline Distance (hands) $[\mathrm{m}]$ & 1 & 700 & 1 \\
\hline Work done $[\mathrm{Nm}]$ & $37 / 26$ & $25,900 / 18,200$ & $37 / 26$ \\
\hline Total work done for hands & \multicolumn{4}{|}{. } \\
\hline
\end{tabular}

The work spent on the external load for lifting, carrying and lowering operations of the school bag before and after improvement is 25,974 and 18,252 [Nm], respectively. Based on this calculation, the total work for carrying the school bag is the sum of all the works mentioned:

$$
W_{h}+W_{\text {internal }}+F_{\text {hands }} * s=25,974+1,152+37 * 700=53,026[\mathrm{Nm}]
$$

Therefore, the total work is $18,252+1,050+26 * 700=37,502[\mathrm{Nm}]$. An important parameter in the calculation of energy is frequency, or how many times the indicated activity is performed per minute. This 
parameter provides the required power for the activity by multiplying the operation by the frequency period. Power consumed during one school day is calculated by the expression:

$$
\begin{gathered}
E=A \cdot f \cdot P \cdot \Theta=53,026 \cdot 0.05 \cdot 0.67 \cdot 1.3=2,309.28[\mathrm{~J} / \mathrm{school} \text { day }] \text { (before improvement) } \\
E=A \cdot f \cdot P \cdot \Theta=37,502 \cdot 0.05 \cdot 0.67 \cdot 1.3=1,633.21[\mathrm{~J} / \text { school day }] \text { (after improvement) }
\end{gathered}
$$

The amount of of Basal metabolic rate (BMR) the students make is

$$
B M R=66.00+(13.70 \cdot M)+(5.00 \cdot H)-(6.80 \cdot Y)=1,126.80)[\mathrm{kcal} / \mathrm{day}]
$$

or $B M R=4,721,292[\mathrm{~J} / \mathrm{day}]$.

The product of BMR converted to [J], load factor and activity period gives the energy consumption based on BMR. For the period of work activities we take into account the duration of the school day, so we get

$$
B M R=4,721,292 \cdot 1.3 \cdot 0.67=4,112,245.33[\mathrm{~J} / \mathrm{school} \mathrm{day}]
$$

Total power consumed during the school day represents the sum of BMR and power consumed during the school day:

$$
\begin{gathered}
E_{u}=E+B M R=2,309.28+4,112,245.33=4,114,554.61[\mathrm{~J} / \text { school day }] \text { (before improvement) } \\
E_{u}=E+B M R=1,633.21+4,112,245.33=4,113,878.54[\mathrm{~J} / \mathrm{school} \text { day }] \text { (after improvement) }
\end{gathered}
$$

\section{Discussion}

A school backpack can cause various problems as well as diseases, some of which can become chronic. Therefore, it is crucial that the school backpack is child-friendly, not too big, properly worn on both shoulders, and that it is not too heavy. It is recommended that the backpack is not more than $10 \%$ of the student's body weight. An overweight school backpack causes muscle tension, joint pain, and health problems, which are associated with lower back pain. A survey was conducted to discuss the feeling of the weight of the carry bag, whether they were tired when carrying it, and whether they felt certain pain in the muscles and spine. The information provided was related to students' standard habits as well as how school bags were carried. The children and their parents answered the eleven questions asked in the questionnaire, and these data provided the basis upon which the complete analysis was performed. The survey included all relevant questions such as 'do children walk to school', 'do they carry their school backpacks on a daily basis', 'does he carry his school backpack on his own', ' does he play sports', 'what is the way of carrying bags'. The answers to the questions asked provided a detailed picture, so it is stated that $84 \%$ of children walk to school, $95 \%$ carry a bag to school every day, $76 \%$ are independent, $62 \%$ do not know if the bag they carry is ergonomically designed. Based on the data obtained, some irregularities and problems with the carrying of school bags can be observed, which could result in the occurrence of health problems, that is, pain in the lower spine.

A survey was conducted to obtain the health status of the students surveyed. Questionnaire (consisting of eight questions, conducted on the same sample as the survey, with the exception that these questions focused on the general health of the student. External load of students under the weight of the school bag relative to the critical point of the lumbar spine L4/L5 indicates that subjects have an increased risk of contracting this particular segment of the spinal column. The maximum pressure exerted at the L4/L5 pressure point may be $3.4[\mathrm{kN}]$. In the United Kingdom, the prevalence of pain in the lumbar spine of eleven year olds is $12 \%$, while as many as $50 \%$ at the age of fifteen $(10,11)$. More than 20,000 injuries caused by heavy bags were treated in clinics across the United States in 2003 (12). Also, the way of carrying a bag is essential for the students (14). However, despite the warnings of experts, school backpacks are becoming more and more heavy, the books 
and other school stuff is increasing, and this directly affects the development and health of the students. The World Health Organization has recommended that the load of a student's bag should not exceed $10 \%$ of the student's body weight. Many countries have defined this by law, stating that the maximum weight of a school bag with accessories and the necessary equipment should not exceed $10 \%$ of the total body weight of a child according to the recommended weight chart of children from 5 to 18 years, given by World Health organization. The essence and main task of this paper is to apply the acquired knowledge, i.e. to regularly inform students, parents, teaching staff what consequences they can leave on the health of students when carrying school bags that are overburdened and inadequate for the students themselves. It is certainly important to involve the media, doctors, as well as all competent in this issue. At the same time, it is important to find an adequate solution for reducing the burden by introducing school lockers, which would reduce the need to carry all the work material (equipment) and textbooks, or transfer the literature to electronic form whereby students would have provided literature and at home to study. The negative impact of the weight of the school backpack, which, in addition to other causes such as: incorrect sitting, lack of physical activity, affects the development of spinal and foot deformities. By analyzing and recording the position of carrying and lifting / lowering the school backpack, it was concluded that the loads acting on L4/L5 in the students were not acceptable, because the software analysis showed that the forces acting on the students were outside the limits of normal, i.e. above 3,400 N. Based on these indicators, the hypothesis of this paper was confirmed, it was confirmed that the school backpack was too heavy and caused excessive loads on the spinal segment L4/L5, and therefore measures and activities had to be taken to reduce the weight of school backpacks.

\section{Conclusions}

The goal is to reduce the weight of school backpacks by $30 \%$ compared to the average weight of school backpacks so far, which would contribute to a better health of students and adequate locomotor development.

\section{References}

[1] S. Kuai, W. Liu, R. Ji and W. Zhou, "The Effect of Lumbar Disc Herniation on Spine Loading Characteristics during Trunk Flexion and Two Types of Picking Up Activities", Journal of Healthcare Engineering vol. 2017, pp 1-11, 2017.

[2] G.B. Andersson, "Epidemiological features of chronic low-back pain", Lancet, 354(9178):581-5, 1999.

[3] J.P. Urban and S. Roberts, "Degeneration of the intervertebral disc", Arthritis Res Ther, ;5(3):120-130, 2003.

[4] L.R. Vialle, EN. Vialle, J.E. Suárez Henao and G . Giraldo, "Lumbar Disc Herniation", Rev Bras Ortop., 45(1):17-22, 2015.

[5] R.M. Amin, N.S. Andrade and B.J. Neuman, "Lumbar Disc Herniation", Curr Rev Musculoskelet Med., 10(4):507-516, 2017.

[6] C.K. Kepler, R.K. Ponnappan, C.A. Tannoury, M.V. Risbud and D.G. Anderson, "The molecular basis of intervertebral disc degeneration",Spine J., 13(3):318-30, 2013.

[7] B.W. Koes, M.W van Tulder and S. Thomas, "Diagnosis and treatment of low back pain", BMJ., 332(7555):1430-4, 2006.

[8] M. Allegri, S. Montella, F. Salici et al, "Mechanisms of low back pain: a guide for diagnosis and therapy", F1000Res., 5:F1000 Faculty Rev-1530, 2016.

[9] H.R Casser, S. Seddigh and M. Rauschmann, "Acute Lumbar Back Pain", Dtsch Arztebl Int., 113(13):223-34, 2016.

[10] P. O'Sullivan, "Diagnosis and classification of chronic low back disorder maladaptive movement and motor control impairments a underlying mechanism, " Man Ther., 10:242-55, 2005.

[11] R.O. Kollock, K.E. Games, A.E. Wilson and J.M. Sefton, "Vehicle Exposure and Spinal Musculature Fatigue in Military Warfighters: A Meta-Analysis", J Athl Train, 51(11):981-90, 2016. 
[12] S. De Sio, V. Traversini, F. Rinaldo et al., "Ergonomic risk and preventive measures of musculoskeletal disorders in the dentistry environment: an umbrella review", PeerJ., 6:e4154, 2018.

[13] F. Veljovic, T. Jurcevic -Lulic and D. Milicic, "Basics of ergonomics", Faculty of Mechanical Engineering, University of Sarajevo, Sarajevo, Bosnia and Herzegovina, 2001.

[14] F. Veljović, S. Burak, A. Voloder, E. Begić, A. Iglica, "Mathematical Model and Analysis of Back and Abdominal Muscle Loading in Relation to Angle of Bending and External Load", TEM Journal, Volume 8, Issue 4, Pages 1326-1330, ISSN 2217-8309, 2019.

[15] S. Burak and F. Veljovic, "Ergonomic Analysis and Redesign of Workspace in Order to Minimize Workers' Workload and Optimize Their Nutrition", TEM Journal, 8(2): 572-6, 2019. 